\title{
An Assessment of Referral System Effectiveness among Health Facilities in Enugu State, Nigeria. (Tertiary, Secondary and Primary Health Facilities)
}

\author{
Article by Ejim Chioma Amanda \\ Public health, Texila American University \\ E-mail: chiomymandy@gmail.com
}

\begin{abstract}
Background: A good referral system serves as a link between the three levels of health care practiced in Nigeria and ensures the continuity of proper health care service delivery. The effectiveness of referral system is an important determinant of the strength of health care service delivery. This study assesses referral system effectiveness among health facilities (primary, secondary and tertiary) in the urban and rural areas using two local government areas in Enugu State. Objective: To assess referral system effectiveness among health facilities in Enugu state Nigeria. Methodology: A cross-sectional epidemiological study of the analytical type was carried out among health workers in the various levels of health facilities within two local governments in the urban and rural areas in Enugu state. Stratified sampling technique was used to select the study participants. A pretested self- administered questionnaire was used to collect data from the respondents and was analysed using SPSS version 23. Results: The mean age of the respondents was $36.26 \pm 8.73(S D)$ years. There was a good overall knowledge and practice of referral given as 392 (95.6\%) and 235 (57.3\%) respectively. Majority $74(47.3 \%)$ of the respondents had a relatively good knowledge of feedback but do not practice the feedback system of referral. Conclusion and Recommendations: The level of awareness of the referral system was impressive. However, the actual referral practice was not very satisfactory due to the lack of proper feedback and poor follow up. Efforts should be made by the agencies involved towards an improvement of the referral system.
\end{abstract}

Keywords: Referral system, Effectiveness, Health facilities, Enugu State.

\section{Introduction}

The referral system is an important tool to ensure effective health care delivery. The Nigerian Health System operates three levels of health care namely, the primary, secondary and tertiary levels which interact through a referral System ${ }^{1,2}$. This is a two- way relationship between health facilities ensuring continuity and complementation of health services. The referral system requires cooperation, coordination and exchange of information between the primary health facility and the first referral hospital during the referral and discharge of patient from the hospital ${ }^{2}$. Referral system is needed in the health system to maximize limited resources, avoid duplication of services, promote cooperation and complementation between primary, secondary and tertiary health facilities. Referral can be either external or internal. External referral is a referral done between one health care facility and another. External referral can be vertical or horizontal. A vertical referral is a referral from a lower to higher facility, or from a higher to lower facility. While a horizontal referral is a referral from one facility to another within the same level but different catchment ${ }^{3}$. For instance, a horizontal referral could be when a patient is referred from one tuberculosis treatment centre to another at the same level but probably due to proximity to patient for easier access to medication. On the other hand, an internal referral is a referral done within the same health care level and facility. For instance, in the same tertiary hospital, a patient being managed for cardiac disease by a cardiology unit could be referred to an ophthalmology unit for the index patient's eyes to be checked. Also, referral can be from public or private sectors through the physician or other health workers. Some patients present directly to the hospital (higher centres) on self-referral by-passing the lower level facilities sometimes based on perceived inadequacies on the lower level facility. The hospital is usually overwhelmed with patients which makes adequate attention difficult to achieve. The tertiary health facilities provide extensive primary and first referral care to clients' mainly in urban settlements. The primary level of care is the entry point to health care 
system and should be able to provide majority of the essential and basic health care services. The secondary level hospitals are to provide general outpatient and inpatient services accepting referrals from urban and rural PHC, while tertiary hospitals are to provide specialized services to referrals from secondary hospitals ${ }^{4}$. In Nigeria, many secondary and tertiary facilities are crowded with people with simple ailments that can be managed at primary health centres while health workers in many of the latter are idle .

There are still no adequate trainings and guidelines to carry out proper referral practice, therefore a study that assesses the effectiveness of referral system and practice by the health workers in the different levels of health care facilities in Nigeria should be carried out. Hence this study was designed to assess the referral system effectiveness among health facilities (primary, secondary and tertiary health facilities) in both urban and rural local governments in Enugu state.

\section{Methodology}

\section{Study area}

The study area is Enugu State. Enugu state was carved out of the old Anambra state in Nigeria and has a population of about 3,267,837. It covers an approximately 12,727 square kilometres. It shares boundaries with six states, boarded by Abia and Imo states in the south, flanked in the east and west by Ebonyi and Anambra states respectively and in the north by Kogi and Benue states. The state lies partly within the tropical rainforest belt to the south, its physical features and vegetation change gradually in the north eastern direction from the tropical rain forest belt to the open woodland and savannah land as it approaches its northern boundary. The native population is entirely Igbo with a sprinkling of Igala near her borders with Kogi state, other ethnic groups are however well represented in the state with a predominance of Hausa and Yoruba communities. The state is well known for its industrial centres and markets with $75 \%$ of the state agrarian. It has about 87 federal establishment. However most of the federal establishment are located at the urban or semi urban centres. Virtually no federal establishment could be found in the rural area ${ }^{6}$.

\section{Study design}

A cross-sectional study of the analytical type was carried out among health workers in the various levels of health facilities within two local governments in the urban and rural areas in Enugu state.

\section{Study population}

The study population are health workers at different levels in the various health facilities in Enugu state. This include health workers from the primary health care facility, secondary health care facility and tertiary health care facility.

\section{Sample size determination}

The sample size was calculated using the Cochrane's formula for cross sectional measurement of proportions which states that

$\mathrm{n}=\mathrm{Z}^{2} \mathrm{pq} / \mathrm{d}^{2}$ where

$\mathrm{n}=$ minimum sample size,

$\mathrm{Z}=$ standard normal deviate that corresponds to $95 \%$ confidence interval $=1.96$

$\mathrm{p}=0.595$

$\mathrm{q}=1-\mathrm{p}=1-0.595=0.405$

$\mathrm{d}=$ minimum tolerable error $=0.05$

Thus, $\mathrm{n}=1.96^{2} \times 0.595 \times 0.405 / 0.05^{2}$

$=370.291$

$\mathrm{n}=370$

Also adding the $10 \%$ non-response rate, the sample size to be used will be:

$10 \%$ of $370=0.1 \times 370=37$

$370+37=407$

Therefore, the sample size for the study is 407 . 


\section{Sampling method}

The target population for this study were health workers in the primary, secondary, and tertiary health facilities in Nkanu West and Enugu North local government areas of Enugu state. In Nkanu West local government area, there are 24 primary health centres, 1 district hospital, 1 cottage hospital, about 10 private clinics and one tertiary hospital. In Enugu North local government area, there are 14 health centres, 1 secondary health facility, about 20 private clinics and one tertiary hospital. A sample of 407 workers was selected.

\section{Data collection}

The data collection tool was a semi structured self-administered questionnaire which was designed using the standard referral guidelines of the Nigerian Federal Ministry of Health. It was divided into 5 sections.

\section{Statistical analysis}

Data generated from this study was entered into the computer for analysis and analysed using the Statistical Package for Social Sciences (SPSS) version 23 (Chicago, Ill) Data was analysed quantitatively and presented in the form of frequency tables.

Knowledge was assessed using a scoring system which was computed using 3 knowledge questions for which yes was scored 1 and No was scored 2. The possible range of scores was 3-6. Scores between 3 and 4 were categorised as Good and those above 4 as Poor.

Attitude was assessed using a scoring system which was computed using 4 attitude questions each with a 5-point Likert scale with scores ranging from 1 to 5 . The possible range of scores was 4- 20 . Scores between 4 and 11 were categorised as Good and those between 12 and 20 as Poor.

Practice was assessed using a scoring system which was computed using 8 practice questions for which Yes was scored 1 and No was scored 2. In other questions which had options of Frequently, Sometimes, Occasionally and Never, a possible range of scores of 1 to 4 was used. The total possible range of scores was 8 to 24. Scores between 8 and 15 were categorised as Good and those between 16 and 24 were categorised as Poor.

Association between categorical variables and the Knowledge, attitude and practice of respondents were assessed using Chi square test with statistical significance assumed at $p<0.05$.

\section{Results}

A total of 407 copies of questionnaires were distributed and retrieved. This gives a response rate of $100 \%$.

Table 4.1 shows the socio-demographic variables of the respondents. The mean age of the respondents was $36.26 \pm 8.73$ (SD) years. About half of each of the respondents were male (202 / 407) or female (208/407) respectively, majority 63.4\% (260/407) were married. Those who attained educational achievement up to tertiary and secondary level 48.5\% (198) had the same and the highest educational strata. The mean year of service of the respondents was $9.89 \pm 7.48$ while the majority of the respondents were doctors $53.9 \%$ (219). The teaching hospital has the highest proportion $42.3 \%$ (170) as work place of the respondents.

There was no statistically significant relationship between knowledge category and age $(p=0.943)$. However there was a statistically significant association between age category and practice $(p=19.119)$

Table 4.2 shows the knowledge level of the respondents. Most of the respondents had a good knowledge of referral, 95.6\% (392). Almost all the respondents 99.8\% (406) of the respondents have heard about referral. The most common source of information was health education $84.9 \%$, followed by colleagues $23.7 \%$, radio $14.1 \%$, television $9.3 \%$, and friends/family being the least being $8.0 \%$.

Table 4.3 shows the attitude to referral practice among the respondents. Most of the respondents 91.5 $\%$ had a positive attitude towards referral practice. Almost all the respondents $97.1 \%$ (398) agreed that referral was done to patient's good, as well as majority $94.4 \%$ (387) agreed that they referred patient when necessary. On the other hand, more than half of the respondents $86.4 \%$ (354) agreed that referral made them look like they do not know their work. 
Tables 4.4 and 4.5 show the level of referral practice among the respondents. Most of the respondents $73.7 \%$ (302) refer patients from their centre to other health facilities, with the highest number $(86.1 \%)$ of reason for referral being to ensure that patients receive advanced treatment and lowest number (3.6\%) of reason for referral being that they do not want patient to die in their facility. About half of the respondents $(50.2 \%)$ were noted to receive feedback occasionally from the referral centres that they refer their patients to while $47.3 \%$ were noted to also occasionally provide feedback to the centres that refer patients to them. $41.2 \%$ of the respondents were noted to record the details of the patients in the referral register sometimes. While $68 \%$ of the respondents collect the details of patients such as phone numbers or address, $33.9 \%$ actually do home visitation to the patients. Majority of the respondents $65.4 \%$ do not have an ambulance at their health care facility. Meanwhile amongst the $34.6 \%$ respondents that have an ambulance, only $87.9 \%$ of the ambulances are functional and being used.

Table 4.6 shows the factors that influence referral practice among the respondents. From the table, $50.8 \%$ of the respondents were noted not have referral forms at their centres and majority $59.8 \%$ of the respondents have never received a training on referral. Most of the respondents occasionally had available at their centres, the referral slip, the referral form, the referral registers and the phone registers as was seen in their response of $36.1 \%, 33.4 \%, 31.7 \%$ and $30.2 \%$ respectively.

\section{Discussion of findings}

Majority of the respondents in this study were married and within the age group of 30-39, with the mean standard deviation being $36.26 \pm 8.73$ (SD) years. This is in conformity with the average working age group and also comparable with a study carried out in Gombe state Nigeria ${ }^{7}$ while it contrasts with a study done at Benin Edo state Nigeria ${ }^{8}$. The reason for the differences may be due to a smaller sample size used in the study. The majority of professional cadre of the respondents was mostly doctors whom were mainly from the teaching hospitals and being followed by the CHEWs who formed that of the PHC workers. This is in line with a study done in Kaduna state Nigeria ${ }^{9}$ but however differs in terms of the cadre at the PHC level in a study done in the United State ${ }^{10}$. The similarity may be because in the PHC centres in Nigeria and most African countries, there is still lack of adequate professional health work force, therefore most of the health workers found there are these CHEWs with some being volunteer workers as well.

There was a good overall knowledge on referral system among the respondents. Again, majority were noted to have their main source of information as health education followed by their colleagues. This corresponds with a similar study done in South Eastern Nigeria ${ }^{11}$ but differs from a study done in North-Western Nigeria ${ }^{9}$ and another done in $\operatorname{Iran}^{5}$ where there was a poor knowledge of referral among the health workers. The reason for the generally good knowledge of referral may be owing to the fact that most of the PHC and secondary health care facilities lack adequate professional health care workers and the infrastructure to handle most of the cases that presents to them, thus they are trained to refer these cases for appropriate health care services. On the other hand, there may be insufficient awareness and provisions for referral in these study areas with poor knowledge.

The overall attitude towards referral was positive as majority of the respondents had a good reason for referring the patients that needed to be referred, even though a great number of respondents which was mostly among the health workers at the PHCs still think that they will be seen as being incompetent. Proper knowledge is one factor that influences the attitude of the health care workers especially those at the lower levels of health care. A study done in the northern area of Nigeria showed a poor attitude towards referral ${ }^{12}$.

It was noted from the study, that there was a good overall referral practice (57.3\%) though just slightly above half of the respondents. Most of them had good reasons to refer and claim to refer patients to the other higher levels of health care centres, the tertiary and the secondary levels. While even among the tertiary level, they also practice the horizontal referral within the same level or facility from one specialty to another. Most of the respondents were noted to refer and also have patients being referred to them only occasionally. Similar results were obtained from a study done at Gombe state Northern Nigeria $^{7}$ and Benin state Nigeria ${ }^{8}$ where the most of the respondents were noted to refer their patients and most of them affirmed that they do occasionally. On other hand, another study done in Kaduna state Nigeria showed a poor referral practice among health workers 9 . 
There is no proper feedback or practice of the two-way referral system which would have benefited both the referring health worker, the referred health worker and even the patient alike.

A proper knowledge of the referral system and availability of the necessary elements to carry out the practice will in turn lead to a good referral practice. From this study, most of the respondents were noted not to have access to an ambulance and even amongst those that had, some were not functional. This would further impede the actualization of a good referral practice because a patient may have been referred but does not have a means of getting to the referred facility as urgently as may be necessary.

A study done in Kenya showed that the availability of necessary infrastructure and transport facilities for the transportation of patients, specimens and other parameters were not sufficient ${ }^{13}$.

From the study, most of the respondents have never received any form of training regarding referral practice. Also, some of the factors which influence the referral practice and thereby determine its proper application or not include the referral slips, referral form, referral register, phone register was accessed and it was noted that most of the respondents do not really have proper access to these tools that will facilitate their practice of referral. This is in line with and comparable to the study done in Kenya ${ }^{13}$ which noted the unavailability of these factors at the facilities where they are needed.

A study done in the United Kingdom also noted lack of proper communication as part of the hindrances to appropriate referral practice ${ }^{14}$.

\section{Conclusion}

This study on referral system was carried out among health workers at the tertiary, secondary and primary levels of health care in both the urban and rural areas selected in Enugu state Nigeria to assess the effectiveness of the system. Findings have shown that while the level of awareness was impressive, the actual practice of the referral system (two-way referral system) however was not satisfactory as most of the health workers especially at primary health care level. The lack of proper feedback and poor follow up hinders effectiveness of the referral system at the various levels of health care in Nigeria. Therefore, efforts should be made by the agencies and policy makers to improve the communication and synergy of the various levels of health care.

Table 1. Socio-demographic variables

\begin{tabular}{|lll|}
\hline Socio-demographic variables & Frequency & Percent \\
Age in years & & \\
$20-29$ & 91 & 23.0 \\
$30-39$ & 177 & 44.7 \\
$40-49$ & 100 & 24.4 \\
$50-59$ & 36 & 9.1 \\
$60-69$ & 6 & 1.5 \\
Mean \pm SD & $\mathbf{3 6 . 2 6} \pm \mathbf{8 . 7 3 1}$ & \\
Years of service & & \\
$1-5$ & 135 & 34.7 \\
$6-10$ & 128 & 32.9 \\
$11-20$ & 81 & 20.8 \\
$21-30$ & 41 & 10.5 \\
$31-40$ & 4 & 1.0 \\
Mean \pm SD & $\mathbf{9 . 8 9} \pm \mathbf{7 . 4 8 7}$ & \\
Sex & & \\
Male & 202 & 49.6 \\
Female & 208 & 50.4 \\
Educational level & & \\
No formal & 2 & 0.5 \\
Primary & 10 & 2.5 \\
Secondary & 198 & 48.5 \\
Tertiary & 198 & 48.5 \\
Marital status & & \\
\hline
\end{tabular}


DOI: 10.21522/TIJPH.2013.SE.19.01.Art017

ISSN: 2520-3134

\begin{tabular}{|lll|}
\hline Single & 130 & 31.7 \\
Married & 260 & 63.4 \\
Others* & 20 & 4.9 \\
Professional cadre & & \\
Doctors & 219 & 53.9 \\
Nurses & 48 & 11.8 \\
Pharmacist & 8 & 2.0 \\
Lab scientist & 19 & 4.7 \\
CHEW & 80 & 19.7 \\
CHO & 36 & 7.9 \\
Place of work & & \\
PHC & 133 & 33.1 \\
Private & 47 & 11.7 \\
District hospital & 8 & 2.0 \\
Gen hospital & 31 & 7.7 \\
CHC & 13 & 3.2 \\
Teaching hospital & 170 & 42.3 \\
\hline
\end{tabular}

Table 2. Knowledge of referral system

\begin{tabular}{|lll|}
\hline Heard about referrals & $\begin{array}{l}\text { Yes } \\
\text { Freq (\%) }\end{array}$ & $\begin{array}{l}\text { No } \\
\text { Freq (\%) }\end{array}$ \\
\hline Yes & 406 & 99.8 \\
No & 1 & 0.2 \\
& Freq (\%) & Freq (\%) \\
Sources of information & & \\
TV & $38(9.3)$ & $372(90.7)$ \\
Radio & $58(14.1)$ & $352(85.9)$ \\
Health education & $348(84.9)$ & $62(15.1)$ \\
Colleagues & $97(23.7)$ & $313(76.3)$ \\
Family/friends & $33(8.0)$ & $377(92.0)$ \\
& & \\
Level of the referral system & Freq & \% \\
Primary & 28 & 6.9 \\
Secondary & 49 & 12.0 \\
Tertiary & 331 & 81.1 \\
& Yes F (\%) & No F (\%) \\
Heard about follow up & $386(94.1)$ & $24(5.9)$ \\
Refer patients/follow up & $302(73.7)$ & $108(26.3)$ \\
Heard referral guidelines & $286(69.8)$ & $124(30.2)$ \\
Overall Knowledge & & \\
Good & $392(95.6 \%)$ & \\
Poor & $17(4.1 \%)$ & \\
\hline
\end{tabular}

Table 3. Attitude to referral practices

\begin{tabular}{|lll|}
\hline Variables & Positive f (\%) & $\begin{array}{l}\text { Negative f } \\
(\%)\end{array}$ \\
$\begin{array}{l}\text { Referral done to } \\
\text { patients good }\end{array}$ & $398(97.1)$ & $13(2.9)$ \\
$\begin{array}{l}\text { Referral is } \\
\text { beneficial to health } \\
\text { worker }\end{array}$ & $361(88.0)$ & $48(12.0)$ \\
$\begin{array}{l}\text { Like referring when } \\
\text { necessary }\end{array}$ & $387(94.4)$ & $22(5.6)$ \\
\hline
\end{tabular}




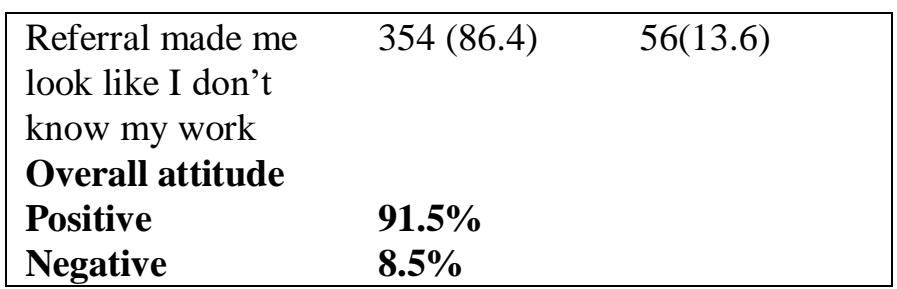

Table 4. Referral practices

\begin{tabular}{|c|c|c|}
\hline Variables & Yes (\%) & No $(\%)$ \\
\hline $\begin{array}{l}\text { Refer patients from centre } \\
\text { Reasons for referrals }\end{array}$ & $302(73.7)$ & $108(26.3)$ \\
\hline $\begin{array}{l}\text { Ensure patients gets advanced } \\
\text { treatment }\end{array}$ & 353(86.1) & $57(13.9)$ \\
\hline $\begin{array}{l}\text { There are investigations we } \\
\text { can't do }\end{array}$ & $158(38.5$ & $252(61.5)$ \\
\hline $\begin{array}{l}\text { Don't want patient to die in my } \\
\text { facility }\end{array}$ & $15(3.6)$ & $395(96.4)$ \\
\hline $\begin{array}{l}\text { How often do you refer to } \\
\text { other centres }\end{array}$ & Freq & $\%$ \\
\hline Frequently & 56 & 13.7 \\
\hline Sometimes & 234 & 57.1 \\
\hline Occasionally & 99 & 24.1 \\
\hline Never & 21 & 5.1 \\
\hline $\begin{array}{l}\text { How often are patients } \\
\text { referred to your centre }\end{array}$ & Freq & $\%$ \\
\hline Frequently & 145 & 35.4 \\
\hline Sometimes & 87 & 21.2 \\
\hline Occasionally & 157 & 38.5 \\
\hline Never & 21 & 5.1 \\
\hline $\begin{array}{l}\text { How often do you get } \\
\text { feedback after you refer }\end{array}$ & Freq & $\%$ \\
\hline Frequently & 32 & 7.8 \\
\hline Sometimes & 82 & 20.0 \\
\hline Occasionally & 206 & 50.2 \\
\hline Never & 88 & 21.5 \\
\hline \multicolumn{3}{|l|}{$\begin{array}{l}\text { How often do you provide } \\
\text { feedback }\end{array}$} \\
\hline Frequently & 40 & 9.8 \\
\hline Sometimes & 78 & 19.0 \\
\hline Occasionally & 194 & 47.3 \\
\hline Never & 98 & 23.9 \\
\hline
\end{tabular}

Table 5. Referral practices (2)

\begin{tabular}{|lll|}
\hline $\begin{array}{l}\text { How often do you record } \\
\text { details in the referral register }\end{array}$ & Freq & $\%$ \\
Frequently & 63 & 15.4 \\
Sometimes & 169 & 41.2 \\
Occasionally & 46 & 11.2 \\
Never & 132 & 32.2 \\
& Yes (\%) & No (\%) \\
Do you collect details & $282(68.8)$ & $128(31.2)$ \\
Do you refer on request & $241(58.8)$ & $169(41.2)$ \\
Doing home visits & $139(33.9)$ & $271(66.1)$ \\
\hline
\end{tabular}




\begin{tabular}{|lll|}
\hline Has ambulance & $142(34.6)$ & $268(65.4)$ \\
Functional ambulance & Freq & \% \\
Yes & 124 & 87.9 \\
No & 18 & 12.1 \\
Overall Practice & & \\
Good & $235(57.3)$ & \\
Poor & $175(42.7)$ & \\
\hline
\end{tabular}

Table 6. Factors that influence referral practice

\begin{tabular}{|lll|}
\hline & Yes $(\%)$ & No $(\%)$ \\
Do you have referral forms & $200(48.8)$ & $206(50.2)$ \\
Have you been trained & $161(39.3)$ & $245(59.8)$ \\
Availability of; & Frequency & Percent (\%) \\
Referral Slip & & \\
Always & 60 & 14.6 \\
Frequently & 41 & 10.0 \\
Occasionally & 148 & 36.1 \\
Never & 147 & 35.9 \\
Referral Forms & & \\
Always & 27 & 6.6 \\
Frequently & 15 & 3.7 \\
Occasionally & 137 & 33.4 \\
Never & 216 & 52.7 \\
Referral Register & & \\
Always & 52 & 12.7 \\
Frequently & 30 & 7.3 \\
Occasionally & 130 & 31.7 \\
Never & 175 & 42.7 \\
Phone register containing & & \\
names and phone numbers & & \\
Always & 47 & 11.5 \\
Frequently & 39 & 9.5 \\
Occasionally & 124 & 30.2 \\
Never & 183 & 44.6 \\
\hline
\end{tabular}

\section{References}

[1]. Abodunrin OL, Akande TM, Osagbemi GK. Awareness and perception towards referral in healthcare: A study of adult residents in Ilorin, Nigeria; Annals Afri Mal,2010: 9 (3): 176-80.

[2]. Agofure O, Absalom B. Knowledge of referral and feedback system among health workers in Billiri local government area of Gombe state Nigeria. European J of Pharm and Med Research 2016: 3(11), 111-115.

[3]. Asuke S, Ibrahim S M, Sabitu K, Asuke A U, Igbaver I I, Joseph S. A comparison of referral among primary health care workers in urban and rural local government in North- West Nigeria. Journal of Medicine in the Tropics (2016) 18:2:93-97.

[4]. Bossyns P, Van Lerberghe W. The weakest link: Competence and prestige as constraints to referral by isolated nurses in rural Niger. Hum Resour Health 2004; 21.

[5]. Enabulele O, Enabulele J.E. A look at the two-way referral system: experience and perception of its handling by medical consultants and specialists among private medical practitioners in Nigeria. Int J Fam Commun Med 2018; 2(3):86-92. DOI:10.15406/ijfcm.2018.02.00054.

[6]. Ekwueme O C. Knowledge and Practice of Patients' Referrals Among Nurses and Nurse Assistants at The Primary Health Care (PHC) Centres in Enugu, Nigeria, Ebonyi Med J 2010; 9(2). 
[7]. Federal Ministry of Health Revised National Policy 2004; 5-17

[8]. Forrest C B, Nutting P A, Schrader S V. Rhode C, Starfield B, Primary care physician specialty referral decision making: patient, physician and health care system determinant. Medical Decision Making 2006: JanFeb. DOI: 10.1177/0272989X05284110

[9]. Health Reform Foundation of Nigeria. History of the Nigerian Health Sector. Nigerian Health Review 2006 Herfon, 2006: 1-13.

[10]. Kariri J K, Ben O O, Susan N. Challenges facing implementation of referral system for quality health care services in Kiambu county Kenya. iMedPub Journal http://journals.imedpub.com DOI:10.21767/22549137.100067

[11]. Obionu C, N. Primary Health Care for Developing countries 2016: 25-27, 236

[12]. Osibogun A. The role of health center in the rational use of health resources, paper presented at the $17^{\text {th }}$ Annual scientific conference of Association of Community Physicians of Nigeria. March 1996: 4-9

[13]. Okafor S. Inequalities in the distribution of health care facilities in Nigeria, geographical and medical viewpoints 2007: 49- 55

[14]. Reid C, Moorthy C, Forshaw K. Referral patterns: an audit into referral practice among doctors in emergency medicine: Emerg Med J 2005;22:355-358. DOI: 10.1136/emj.2003.008409. 